\title{
Analogical encoding facilitates knowledge transfer in negotiation
}

\author{
JEFFREY LOEWENSTEIN, LEIGH THOMPSON, and DEDRE GENTNER \\ Northwestern University, Evanston, Illinois
}

\begin{abstract}
Information learned in one situation often fails to transfer to a similarly structured situation. However, prior findings suggest that comparing two or more instances that embody the same principle can promote abstraction of a schema that can be transferred to new situations. In two lines of research, we examined the effects of analogical encoding on knowledge transfer in negotiation situations. In Experiment 1, undergraduates were more likely to propose optimal negotiation strategies and less likely to propose compromises (a suboptimal strategy) when they received analogy training. In Experiment 2, graduate management students who drew an analogy from two cases were nearly three times more likely to incorporate the strategy from the training cases into their negotiations than were students given the same cases separately. For both novices and experienced participants, the comparison process can be an efficient means of abstracting principles for later application.
\end{abstract}

The premise of our educational system is that what is learned in the classroom transfers beyond the school walls. More generally, the presumption that knowledge is portable underlies much of our intuition about how we solve problems and make decisions. However, empirical evidence paints a rather gloomy picture of people's ability to retrieve relevant knowledge when solving a problem (see Reeves \& Weisberg, 1994, for a recent review). This is particularly striking in studies of learning by example. We claim that analogical encoding promotes transfer. By analogical encoding, we mean the process of comparing two examples and deriving an abstraction on the basis of their commonalities.

Although people often rely on previously learned examples to suggest possible solutions to current problems (see, e.g., Gentner, Holyoak, \& Kokinov, in press; Pirolli \& Anderson, 1985; Ross, 1984), the ability to take full advantage of prior experience is highly limited. For example, having solved one problem often does not help in solving an analogous problem when the two problems come from different contexts (see, e.g., Catrambone \& Holyoak, 1989; Gick \& Holyoak, 1980, 1983; Keane, 1988; Novick, 1988; Reed, Dempster, \& Ettinger, 1985; Reed, Ernst, \& Banerji, 1974; Ross, 1987, 1989a, 1989b; Ross \& Kennedy, 1990; Schumacher \& Gentner, 1988; Simon \& Hayes, 1976; see

The research was supported by National Science Foundation Grant SES-9210298, awarded to the second author, and by National Science Foundation Grant SBR-9511757 and Office of Naval Research Grant N00014-92-J-1098, awarded to the third author. We thank Max Bazerman and Doug Medin, as well as the other participants in the New Ideas in Decision Making 1997 conference, for their input. We also thank Charles Naquin and Laura Kray for help in data collection and Phil Wolff and the entire Similarity and Analogy group at Northwestern University for helpful discussions. Correspondence concerning this article should be addressed to J. Loewenstein, Department of Psychology, Northwestern University, 2029 Sheridan Road, Evanston, IL 602082710 (e-mail: loewenstein(a)nwu.edu)
Bransford, Franks, Vye, \& Sherwood, 1989, and Reeves \& Weisberg, 1994, for reviews). For example, Gick \& Holyoak (1980, 1983) explored people's ability to solve Duncker's (1945) radiation problem. The problem is how to use a ray to destroy a patient's tumor, given that the ray at full strength will destroy the healthy tissue en route to the tumor. Only about $10 \%$ of the people solve this problem. Gick and Holyoak asked whether performance would improve if the participants were given an analogous problem prior to being given the radiation problem. In the analogous problem, a general needs to capture a fortress but is prevented from making a frontal attack by the entire army. One solution is to divide the army and converge on the fortress from many sides. An analogous solution is possible for the radiation problem: one can converge on the tumor with lowstrength rays from multiple sides. The results were striking. Even when given the tumor problem immediately after the fortress problem, only $41 \%$ of the participants spontaneously applied the convergence solution to the tumor problem. Yet when simply told to "think about the earlier problem," the participants' solution rate rose to around $85 \%$. The participants had retained the knowledge but had failed to access it when given an analogous situation. Applying previously learned knowledge to new situations appears to be surprisingly difficult.

There is evidence that similarity-based retrieval from memory occurs most reliably by surface similarity, not by deep analogical similarity. When people encounter a new situation or problem, they are reminded not of prior problems with the same underlying relations and causal structure, but of problems with the same surface features (Gentner, Rattermann, \& Forbus, 1993; Ross, 1987, 1989a). In a systematic study of retrieval, Gentner, Rattermann, and Forbus gave people a set of stories and later tested for remindings, given probe stories. The probe stories could match on surface features (e.g., setting and objects), on higher order relational structure (e.g., causal 
plot structure), on both, or on neither. Gentner et al. (1993) found a clear dissociation. Only stories containing surface feature matches were likely to be recalled $(55 \%$ of the time, as compared with $12 \%$ of the time for recall based on purely analogical matches). However, only relational matches were rated as being useful for making inferences. Likewise, Ross (1987, 1989a, 1989b) found that people attempting to solve mathematics problems were most often reminded of previously learned examples with surface similarities, rather than of examples with common structure. Thus, the abstract knowledge embedded in prior examples is often not accessed, despite the fact that, once it is called to attention, people regard it to be helpful (Forbus, Gentner, \& Law, 1995; Gentner \& Landers, 1985; Gentner et al., 1993; Gick \& Holyoak, 1980, 1983; Holyoak \& Koh, 1987; Reeves \& Weisberg, 1994; Ross, 1987, 1989a).

The previous examples showed that surface similarity matches predominate in novices' memory retrievals. Novick (1988; Novick \& Holyoak, 1991) found that experts were able to retrieve more relational matches than were novices, as measured by their increased likelihood of transfer. Forbus et al. (1995) speculated that experts show an improvement in transfer owing to the consistency with which they represent problems, particularly through encoding relations uniformly across contexts. Using the same relational terms across problems facilitates retrieval on the basis of common relations (Clement, Mawby, \& Giles, 1994).

If relational similarity between the probe and the stored item increases the likelihood of analogical transfer, appropriate transfer can be promoted by making the relational structure explicit during the original encoding. One method for doing this is to induce a comparison with another relationally similar item during the study phase. According to Gentner and Markman (1997), comparison entails a structural alignment and mapping process that highlights the similar aspects of the two examples (see, also, Falkenhainer, Forbus, \& Gentner, 1989; Holyoak \& Thagard, 1995; Medin, Goldstone, \& Gentner, 1993). Focusing on shared aspects between examples promotes the abstraction of a common relational structure that can then be stored as a schema. There is evidence that people draw such abstractions readily in the process of making comparisons (e.g., Brown, Kane, \& Echols, 1986; Lassaline \& Murphy, 1996, 1998; Markman \& Gentner, $1993)$ and that this process facilitates subsequent relational transfer (Catrambone \& Holyoak, 1989; Gick \& Holyoak, 1983; Kotovsky \& Gentner, 1996; Loewenstein \& Gentner, 1997, 1999; Ross, 1987; Ross \& Kennedy, 1990). These findings suggest that analogical encodingencoding that results from processing two analoguesfosters knowledge transfer to subsequent situations with similar relational structures. If so, we can promote transfer by inducing appropriate comparisons.

Prior research has focused on a somewhat circumscribed range of tasks and problems, such as mathematics problem solving and laboratory recall tasks. In order to study analogical encoding in rich domains and realworld settings, we focused on negotiation, an everyday task that is, nonetheless, intricate and difficult (Thompson, 1998). Negotiation is a domain that intrinsically possesses a high level of real-world richness. If our hypothesis is correct, transfer of learned negotiation strategies requires that the abstract principles that underlie successful negotiation be accessed and adapted to vastly different contexts. By its very richness, negotiation thus poses a challenge to an account of cross-domain analogizing.

Another advantage of negotiation, from our point of view, is that the skills of good negotiation appear to be nonobvious. People often make suboptimal negotiation agreements in which the maximal potential gains are not realized by either party. Consider the case of lose-lose outcomes: Fifty percent of the negotiators fail to realize that they have perfectly compatible interests with the other party, and $20 \%$ of the pairs fail to settle on the value that both parties prefer (Thompson \& Hrebec, 1996). Thompson and Hrebec noted that the cost of poor negotiating can range from as little as a few lost hours to as much as millions of lost dollars. Worse, even seasoned executives often have little intuition for when they have failed to negotiate effectively. Often, when their mistakes are revealed to them, students feel that they understand fully, yet go on to repeat their errors in subsequent negotiations.

A related advantage of negotiation is that participants are highly motivated to do well. Professional managers are especially motivated to learn to negotiate effectively. At Northwestern University's Kellogg School of Management alone, roughly 900 masters of management students and 600 executives annually pay thousands of dollars to learn how to negotiate. In our second experiment, we drew on this population.

\section{OVERVIEW OF THE RESEARCH}

We will describe two lines of research that address whether and how comparison during instruction can promote subsequent transfer. In both approaches, we compared the transfer ability of people who received analogical comparisons during learning with that of people who did not. The first line of research could be described as a maximal intervention. This approach was designed to lead participants explicitly through the steps of a comparison. In the second line of research, which could be described as a minimal intervention, the only variable was whether participants were instructed to make a comparison.

Two negotiation strategies were studied. The first is called a tradeoff, also known as logrolling in the negotiation literature (Froman \& Cohen, 1970). Tradeoffs capitalize on the potential generated when each party has high interest in one issue and less interest in another issue. Provided that one party's high-interest issue is the other party's low-interest issue, both parties can get what they most want by giving up something they consider less valuable. For example, two people going out for dinner and a movie could compromise on where to eat and what 
movie to see; but if one person cares mainly about the food and the other about the movie, they can increase their overall satisfaction by having the former choose the restaurant and the latter choose the film.

The second principle is called a contingency contract (Lax \& Sebenius, 1986). Contingency contracts capitalize on parties' differing expectations regarding the outcome of a future event. Each party is willing to proceed with an agreement by stating terms for the outcome each thinks will occur, thereby minimizing risk and maximizing expected outcomes. For instance, a producer and a theater owner are at an impasse over negotiating costs associated with mounting a new production: The producer predicts sold-out shows and demands a correspondingly high price, whereas the theater owner has more modest expectations and, thereby, wishes to minimize costs. Rather than compromising on a midpoint between their initial proposals, they can agree that the producer will get $60 \%$ of the revenues if more than 90,000 seats are sold, but only $40 \%$ of the revenues if fewer seats are sold.

Both negotiation strategies deal with the nonobvious task of integrative bargaining. The tradeoff and contingency contract principles maximize individual parties' interests, as well as joint gain. However, these useful principles rarely occur to people during ordinary negotiation situations. Instead, the most common solution is the compromise solution in which parties make concessions to arrive at a middle ground on each issue in conflict.

Our first studies tested transfer of both the tradeoff and the contingency contract principles. Experiment $1 \mathrm{~A}$ was designed to assess participants' baseline tendency to generate compromise, tradeoff, and contingency contract solutions. Experiment 1B was a test of the role of comparison in transfer, using a maximal training method. Experiments $1 \mathrm{~A}$ and $\mathrm{1B}$ had two phases: a training phase and a test phase. All the participants in these experiments read two negotiations during the training phase-one involving a tradeoff and one involving a contingency contract. The test phase consisted of an incomplete negotiation that could be completed by using either principle. The participants were given two opportunities to write completions for the test negotiation and, thus, could have transferred knowledge gained from both prior stories. Our prediction was that the participants would only transfer a negotiation strategy if they had compared multiple examples of that strategy during the learning phase.

\section{EXPERIMENT 1A Baseline}

\footnotetext{
Method

Participants. The participants were 16 undergraduates at Northwestern University, who received course credit in psychology.

Materials and Procedure. Packets were generated containing three two- to three-page transcripts of negotiations. There were two study transcripts: (1) an example of the tradeoff principle, written in the context of a job negotiation between a student and an employer, and (2) an example of the contingency contract ${ }^{1}$ principle, written in the context of a computer purchase by a student from a used computer salesman. The test transcript was left incomplete, so that
}

either principle could be used to solve the negotiation, and was written in the context of a lease negotiation by a student and a landlord.

The participants first read one of the study transcripts, answered comprehension checks to ensure that they understood the negotiation, and wrote a summary of the negotiation. The participants then read the second study transcript, answered comprehension checks, and wrote a summary. Finally, the participants read the test transcript and went through a series of questions. First, they wrote a completion that they deemed fair to both parties. Next, they were asked if they had recalled the earlier negotiations they had read. Finally, they were prompted to write another completion to the negotiation and, if they could, to say whether it was a better solution than their first attempt. This allowed the participants to write both tradeoff and contingency contract solutions, if they saw connections between both study cases and the test problem, or to write one of these solutions, if they only realized it could be used after being asked about their recall.

\section{Results and Conclusions}

The participants nearly exclusively wrote compromises. Fully 15 of the 16 participants ( $94 \%$ ) wrote at least one compromise solution for their negotiation completions. Only 3 of the 16 participants (19\%) wrote a completion using the tradeoff principle ( 2 of them prior to the question on their recall, and 1 afterwards), and none of the participants wrote a completion using the contingency contract principle. The fact that the participants still wrote compromises immediately after reading examples of the tradeoff and contingency contract solutions attests to the strength of compromise as a default negotiation settlement.

Despite the fact that the participants seldom used the negotiation strategies from the study cases to provide an answer to the test negotiation, a majority $(10 / 16$, or $63 \%)$ of the participants said they were reminded of at least one of the previous cases; of this group, most $(8 / 10$, or $80 \%$ ) were reminded of the tradeoff negotiation. Among this group, 3 participants actually did write tradeoffs; however, it may be overly generous to attribute a strong link between their reminding and their solution, since 5 other participants had the same reminding but failed to generate a tradeoff solution. Asking the reminding questions appeared to have little influence on the participants' use of the previous cases. One participant did write a tradeoff after the recall question, but 5 other participants wrote new compromise conclusions. The 10 remaining participants wrote either nothing or the same agreement they had written the first time. These results suggest that the participants were not strongly reminded of the initial cases in meaningful ways, since they failed to use the solutions in those cases to solve the test problem. This result supports previous research showing little spontaneous use of a prior example when solving an analogous problem (e.g., Gick \& Holyoak, 1980; Ross, 1987).

\section{EXPERIMENT 1B Maximal Analogy Training}

Given that simply reading and summarizing negotiations that illustrated tradeoff and contingency contract principles were insufficient for transfer, we investigated 
analogical encoding. In Experiment IB, we devised a maximal analogy intervention in order to give the participants strong support for learning either tradeoffs or contingency contracts. Our prediction was that instructing undergraduates to compare multiple examples should facilitate their transferring the studied strategy to the test negotiation. To demonstrate that the gain was specific to the principle for which the participants received analogies and was not the result of some overall facilitation, we gave half the participants training on the tradeoff principle and the other half training on the contingency contract principle. We predicted that the participants would exceed baseline performance in their negotiation completions only for the strategy for which they had received analogy training.

\section{Method}

Participants. The participants were 32 undergraduates at Northwestern University from the same population as that used in Experiment $1 \mathrm{~A}$. Half the participants were randomly assigned to the tradeoff condition, the other half to the contingency contract condition.

Materials and Procedure. The materials and procedure were similar to those of Experiment 1A. The major difference was that, in the present experiment, the participants received intense analogy training after reading the second negotiation, instead of writing a summary. The analogy training consisted of (1) a definition of the principle, (2) an analogy presented with accompanying diagrams, (3) a second analogy presented in paragraph form, and (4) a mapping task that required stating correspondences between the second analogue and the study negotiation (see Appendix A for an example). Thus, every attempt was made to encourage students to make explicit comparisons between the study negotiation and other examples of the negotiation principle.

\section{Results and Conclusions}

As was predicted, analogy training led to increased use of the appropriate negotiation principles. The benefits were specific to training: Only the participants receiving analogy training for a principle wrote appreciable numbers of completions using that principle (Table 1). Of the 16 participants in the tradeoff condition, $6(38 \%$; 5 before the recall question and 1 after) used the tradeoff principle in a completion, and only $1(6 \%$; after having already written a tradeoff completion) used the contingency contract principle. One participant failed to produce a clear completion, and the remaining 9 participants wrote compromises for their completions $(56 \%)$. Of the 16 participants in the contingency contract analogies condition, $11(69 \%$; 7 before the recall question and

Table 1

Proportions of Participants in Experiments $1 \mathrm{~A}$ and $1 \mathrm{~B}$ Writing Tradeoff, Contingency Contract, and Compromise Solutions

\begin{tabular}{|c|c|c|c|c|c|c|}
\hline \multirow[b]{3}{*}{ Training } & \multicolumn{6}{|c|}{ Analogical Encoding } \\
\hline & \multicolumn{2}{|c|}{ Tradeoff } & \multicolumn{2}{|c|}{$\begin{array}{l}\text { Contingency } \\
\text { Contract }\end{array}$} & \multicolumn{2}{|c|}{ Compromise } \\
\hline & Prop & $n$ & Prop & $n$ & Prop & $n$ \\
\hline Baseline (Experiment $1 \mathrm{~A}$ ) & .19 & $3 / 16$ & 0 & $0 / 16$ & 94 & $15 / 16$ \\
\hline Tradeoff & .38 & $6 / 16$ & .06 & $1 / 16$ & .56 & $9 / 16$ \\
\hline Contingency contract & .19 & $3 / 16$ & .69 & $11 / 16$ & .25 & $4 / 16$ \\
\hline
\end{tabular}

4 after) used the contingency contract principle in a completion, and only 3 (19\%; all before the recall question) used the tradeoff principle. There were only 4 participants $(25 \%)$ who wrote neither a tradeoff nor a contingency contract; these people wrote compromises.

Analogy training led to an above-baseline use of tradeoffs: participants produced $38 \%$ tradeoffs in the tradeoff condition, as compared with $19 \%$ in the contingency contract condition and 19\% in Experiment 1A. The same was true for contingency contracts: $69 \%$, as compared with $6 \%$ and $0 \%$, respectively. A Fisher's exact test showed a significant association between type of training and type of response $(p<.001)$. Thus, analogy training appears to have increased transfer specifically for those strategies for which people received analogies. The difference between the number of tradeoff completions made in the tradeoff condition and the number made in the contingency contract condition was not significant by a sign test, but the difference between the number of contingency contract completions was $(p=.006) .^{2}$ Another way of looking at the results is to note that $50 \%$ of the participants in Experiment 1B transferred the solution they were taught, as opposed to $19 \%$ in the baseline study (Experiment 1A). We conclude, first, that there is a default compromise bias and, second, that intensive analogy training leads to a gain in preference for the alternative negotiation strategy that was taught.

These results are encouraging for the position that comparison during learning can improve the likelihood of later abstract transfer in the domain of negotiation. However, this study, like much of the prior research on analogical transfer, concerned transfer within an academic context, using paper-and-pencil tasks. In the next study, we wanted to take on the more general problem of transfer from "bookish" contexts to real-world interactions. Another goal was to investigate a more minimal intervention. The training intervention in Experiment $1 \mathrm{~B}$ was rather strenuous. In Experiment 2, we asked whether positive transfer could be achieved under more natural circumstances. All the participants received the same information, but only some were encouraged to make a comparison.

\section{EXPERIMENT 2}

Receiving pairs of examples has often proven effective for later transfer (Gick \& Holyoak, 1983; Reeves \& Weisberg, 1994; Ross \& Kennedy, 1990) and was arguably the main factor in the success of the analogy training in Experiment 1B. The first goal of our next experiment was to tease apart receiving pairs of examples from comparing pairs of examples. Therefore, all the participants received the same pair of examples. The difference in conditions lay in whether the participants were told to compare the two cases or were simply asked questions about each case separately.

The second goal of the study was to explore the generality of our findings. It has been argued that psycho- 
logical findings of surface-based remindings, as reviewed above, stem from the use of unmotivated participants who fail to encode the materials deeply (e.g., Hammond, Seifert, \& Gray, 1991). Perhaps, for highly motivated participants, who are disposed to engage in active encoding, presenting separate cases would be as effective as inducing comparison. To test this possibly, we chose as participants masters of management students at the Kellogg Graduate School of Management. This is a highly motivated population at a school whose culture encourages working hard and being prepared.

A further issue of generality concerns the transfer task. Whereas most prior research has focused on transfer from one written task to another written task, we studied transfer from a written worksheet to a two-party face-toface negotiation. Our study was conducted as part of a negotiation training class at Kellogg. In this training, participants study roles for a negotiation and then are paired with a partner who studied the opposing role; they must negotiate face to face to create an agreement. In our study, all the participants were given two brief written cases embodying contingency contracts and either compared them or considered them separately. Pairs of participants then negotiated with one another to reach an agreement on a case affording the opportunity to use the contingency contract strategy.

The third goal of the experiment was to address the possibility that presenting an abstract principle, rather than comparing examples, was the reason for some students' success in Experiment 1B. In Experiment 2, no principle was spelled out in detail. To investigate the effects of invoking an abstract principle, we gave half the participants labels for the principle; the other half received no mention of an abstract principle. Therefore, there were four conditions in this experiment, crossing analogical encoding (compare, no-compare) with principle labeling (label, no-label). Our main hypothesis was that the participants in the compare conditions, who were encouraged to analogically encode the principle, would be more likely to transfer the principle to their own negotiation. A further question was whether labeling the principle would promote transfer as well as, or instead of, analogical encoding.

The key measure of interest was the participants' performance on the face-to-face negotiation. We chose a negotiation used in course training that involved a contingency contract. We focused on contingency contracts, because they are both exceptionally difficult to master and exceptionally important to becoming a skilled negotiator. Thus, if comparing cases enables participants to abstract a schema that will permit transfer, participants in the compare conditions should produce more contingency contracts in their face-to-face negotiations than will those in the no-compare conditions. However, if calling attention to the principle is the main determinant of whether people extract a portable schema, participants in the label conditions should produce more contingency contracts in their negotiations than will those in the nolabel conditions.

\section{Method}

Participants. The participants were 116 masters of management students enrolled in a 10 -week course in negotiation at Northwestern University's Kellogg Graduate School of Management. There were 14 dyads in the compare, label condition, 13 dyads in the compare, no-label condition, 16 dyads in the no-compare, label condition, and 15 dyads in the no-compare, no-label condition.

Materials and Procedure. All the students randomly received one of two roles to play in a negotiation (buyer or seller) and had a week to study their roles prior to class. Attached to the information that the students received in order to prepare for the negotiation were two (or three) pages of questions, the first of which was a cover sheet asking general questions about negotiation strategies. The remaining page(s) contained two 225-word summaries of cases involving contingency contracts (Appendix B). In the no-compare conditions, the participants read a case, were asked what had happened, and were asked to describe and evaluate the solution. They then turned the page to read the second case and answer the same questions in regard to it. In the compare conditions, the participants read both cases on one page. They answered the same questions as the no-compare participants, but for both cases simultaneously. They were also asked about similarities and key parallels between the cases. The label conditions differed from the no-label conditions only by consistently mentioning a term for the negotiation strategy (namely, a "bet"). The questions are listed in Table 2.

One week after receiving these materials, the participants were assigned to pairs that engaged in a face-to-face negotiation whose structure allowed for making a contingency contract. All the pairs were chosen so that both members had been in the same training condition. The participants handed in their responses to the study questions prior to negotiating. They were given a maximum of $90 \mathrm{~min}$ to negotiate. They then completed and signed a contract stating the final terms of the agreement

\section{Results and Conclusions}

Negotiation outcomes. The results of the negotiations, shown in Table 3, bore out our prediction that making a comparison promotes analogical transfer. The participants who explicitly compared the cases were three times as likely to use contingency contracts as were those who responded separately $\left[\chi^{2}(1, N=58)=6.913, p<\right.$

Table 2

Instructions for Experiment 2

\section{No compare, No label}

What is going on in this negotiation? Please describe the solution and say how successful you think it is.

No compare, Label

What is going on in this bet negotiation? Please describe the bet solution and say how successful you think it is.

Compare, No label

What is going on in these negotiations? Think about the similarities between these two cases. What are the key parallels in the two negotiations? Please describe the solution and say how successful you think it is.

Compare, Label

What is going on in these bet negotiations? Think about the similarities between these two cases of bets. What are the key parallels in the two negotiations which define what a bet is? Please describe the bet solution and say how successful you think it is 
Table 3

Proportions of Dyads That Made Contingency Contracts in Their Face-to-Face Negotiations

\begin{tabular}{|c|c|c|c|c|c|c|}
\hline \multirow[b]{3}{*}{ Principle Labeling } & \multicolumn{6}{|c|}{ Analogical Encoding } \\
\hline & \multicolumn{2}{|c|}{ Compare } & \multicolumn{2}{|c|}{ No Compare } & \multicolumn{2}{|c|}{ Means } \\
\hline & Prop & $n$ & Prop & $n$ & Prop & $n$ \\
\hline Label & .43 & $6 / 14$ & .19 & $3 / 16$ & .30 & $9 / 30$ \\
\hline No label & .54 & $7 / 13$ & .13 & $2 / 15$ & .32 & $9 / 28$ \\
\hline Means & .48 & $13 / 27$ & .16 & $5 / 31$ & & \\
\hline
\end{tabular}

$.01]$ : Thirteen of the $27(48 \%)$ of the dyads in the compare conditions made contingency contracts, as compared with only 5 of the $31(16 \%)$ of the dyads in the no-compare conditions. In contrast, there was no effect of principle labeling: Thirty percent of the dyads in the label conditions and $32 \%$ of those in the no-label conditions made contingency contracts.

The nature of this study allows a somewhat unusual further prediction-namely, that dyads in the compare conditions should reap more profit than those in the nocompare conditions, because using a contingency contract should result in a higher overall gain, across both parties, than using a compromise solution. Consistent with this reasoning, dyads not using contingency contracts grossed, on average, $\$ 985,000$ from the portion of the negotiation directly relevant to the contingency contract, whereas dyads using the principle grossed, on average, $\$ 1,049,000$, a $\$ 64,000(6 \%)$ advantage $[t(56)=4.372, p<.001]$. Thus, if the compare dyads were more likely to transfer the schema they were taught, they should have achieved better negotiated agreements and higher gross gains. Dyads in the compare conditions gained an average of $\$ 5,000$ $(0.5 \%)$ more from the negotiation than dyads from the no-compare conditions, a nonsignificant difference in the hypothesized direction.

Content analyses of the study responses. We explored what the participants derived from the training cases by examining their written responses to the questions about those cases. The first author and one rater blind to the hypothesis of the experiment rated the quality of the schemas derived from the training cases on a 3 -point scale $(0=$ no aspect of the schema was present, $1=$ some aspect of the schema was present , and $2=$ the full contingency contract schema was present). The raters also judged whether the participants explicitly made a comparison or referred to the first training case when writing about the second training case. The raters agreed on $94 \%$ of their judgments. Once these ratings were made for individuals, a total score for schema quality was generated for each dyad (a simple sum of the individuals' scores, ranging from zero to five) so that this measure could be compared with the likelihood of generating contingency contracts. No differences in ratings were found between the label and the no-label conditions. Therefore, only the compare/no-compare conditions were contrasted. Some participants either did not turn in materials or neglected to write anything on the training ma- terials, resulting in the omission of 8 dyads in the two compare conditions and 5 dyads in the two no-compare conditions. For the remaining dyads, 10 of the $19(53 \%)$ dyads in the compare conditions made bets, as compared with 5 of the $26(19 \%)$ in the no-compare conditions.

In support of the hypothesis that comparison leads to making generalizations, there was a difference in the quality of the schemas derived by the participants in the compare and the no-compare conditions (Table 4). More dyads in the compare conditions (63\%) had total schema ratings greater than 1.0 than did dyads in the no-compare conditions $\left[19 \% ; \chi^{2}(1, N=45)=9.012, p<.005\right]$. None of the dyads in the compare conditions had a total schema rating of zero, meaning no aspect of the contingent contract schema had been derived, whereas $42 \%$ (11/26) of the dyads in the no-compare conditions did. Despite highly similar instructions, comparing two examples, but not separately considering two examples, led participants to derive schemas.

Furthermore, there was a relationship between the quality of the schema that the participants abstracted from the cases and the likelihood of transfer. Dyads whose total schema rating was greater than 1.0 were more likely to make bets $(53 \%)$ than were dyads whose total schema rating was 1.0 or less $\left[28 \% ; \chi^{2}(1, N=45)=4.727, p<\right.$ $.05]$. The trend was present in both the compare and the no-compare conditions: the greater the schema quality, the more likely the dyad was to make a contract by using that schema.

The participants' responses to questions in the learning materials were rated, to determine whether participants in either condition made explicit comparisons between cases or references to the first case when writing about the second. Very few people $(17 \%$, or $9 / 52)$ in the no-compare conditions mentioned the first case when discussing the second. Rather, these participants tended to write about the particular details of each case. Some of the remindings led the no-compare participants to notice the similarity between the cases, but these remindings often resulted in poor statements of the commonalities (e.g., "both cases are about differences of opinion"). Other nocompare participants who experienced remindings stated that they disagreed with the strategy of betting (e.g., "Again, betting is too risky for issues on this scale"). In contrast, nearly everyone $(87 \%$, or $33 / 38)$ in the compare

Table 4

Proportions Making Contingency Contracts by Rated Quality of Derived Schemas

\begin{tabular}{|c|c|c|c|c|}
\hline \multirow{3}{*}{$\begin{array}{c}\text { Total Dyad } \\
\text { Schema Rating }\end{array}$} & \multicolumn{4}{|c|}{ Analogical Encoding } \\
\hline & \multicolumn{2}{|c|}{ Compare } & \multicolumn{2}{|c|}{ No Compare } \\
\hline & Prop & $n$ & Prop & $n$ \\
\hline 0 & - & $0 / 0$ & .09 & $1 / 11$ \\
\hline 1 & .43 & $3 / 7$ & .20 & $2 / 10$ \\
\hline 2 & .38 & $3 / 8$ & .25 & $1 / 4$ \\
\hline 3 & 1.0 & $2 / 2$ & - & $0 / 0$ \\
\hline 4 & 1.0 & $2 / 2$ & 1.0 & $1 / 1$ \\
\hline Total & .53 & $10 / 19$ & .19 & $5 / 26$ \\
\hline
\end{tabular}


conditions wrote about the two cases together, typically in language that evoked the contingency principle. The correlation between reminding (explicitly comparing the two cases) and the rated quality of the schema was high $[r(45)=.539, p<.001]$.

\section{GENERAL DISCUSSION}

In two experiments, making a comparison during learning facilitated knowledge transfer in the domain of negotiation. In the first study, we found that undergraduates given intensive analogy-based training were able to override their dominant tendency to compromise, using, instead, more profitable negotiation principles they had gained from the analogies. The second study utilized more advanced and motivated participants - master of management students-as well as a more lifelike dependent measure, that of performance in a face-to-face negotiation. Here, too, the results showed that inducing analogical encoding often led the participants to transfer the negotiation principle contained in the study cases. These results are particularly striking in view of the subtlety of the manipulation. All the participants received the same study cases in quick succession. Nevertheless, the simple addition of instructions to compare the cases made a large difference in the degree of transfer. Across both experiments, analogy training always resulted in at least double the transfer rate and, in some cases, resulted in a much greater increase.

We have suggested that comparison naturally leads to schema abstraction (Gentner \& Wolff, 1998; also, Gick \& Holyoak, 1983; Ross \& Kennedy, 1990). Consistent with this claim, we found that those participants who compared cases wrote better schemas than did those who considered them separately. We also expected that the quality of the derived schema would be positively related to the likelihood of transfer, and this tendency was found. In a similar prior study that replicated the present finding of an advantage for comparison over studying cases separately (Thompson, Gentner, \& Loewenstein, in press), we also found that high schema quality led to increased transfer. These findings are consistent with prior indications that schema quality is related to transfer likelihood (Gick \& Holyoak, 1983).

Our finding, in Experiment 2, that even minimal comparison of two cases led to better transfer than considering the two cases separately should be extended in future studies to other negotiation principles (e.g., tradeoffs), However, some generality for this effect may be claimed, because of its consistency with the findings of Ross and Kennedy (1990). In their study, the participants learned several probability principles from examples. They were then given a series of analogous test problems and were cued on half of these to use a particular learning example to help arrive at a solution. This cuing should have prompted the participants to recall a specific learning example, compare it with their current problem, and create a generalization on the basis of those two problems- that is, it should have prompted analogical encoding. The critical portion of these studies was a second series of analogous test problems. The participants were more likely to approach a new test problem correctly if they had been cued to compare two examples having the same principle. These results suggest that merely receiving the two initial examples was not as effective as comparing them. Although the participants received two problems for each principle, they showed the greatest success in transferring those principles for which they had received the recall prompt, which, assumably, led them to consider the two initial problems simultaneously. This is consistent with the claim that comparison is a critical factor in learning for transfer.

Deriving principles from examples. There is some evidence that asking people to abstract a general principle from a single example can be beneficial (Ahn, Brewer, \& Mooney, 1992). However, the labeling manipulation in Experiment 2-which might have been expected to call attention to the abstract principle-did not increase transfer likelihood. The labeling manipulation here was relatively subtle. However, in other studies with a methodology similar to those of Experiments $1 \mathrm{~A}$ and 1B, we have used instructions that directly invite participants to link a statement of an abstract principle to an example. The results suggest that comparing examples leads to greater transfer than does receiving a principle and an example (Loewenstein, Gentner, \& Thompson, 1999).

There may be limits on learning via principles. Research carried out by Ross and his colleagues (e.g., Ross \& Kilbane, 1997) suggests that unless there is a close connection between an example and a principle, people may not be able to take advantage of an abstract principle. Ross and Kilbane (1997) found that participants attempting to learn probability principles tended to recall previously learned examples, but if the principle was divorced from the example, they had difficulty applying it to the current problem.

Using analogies to improve case-based training. The traditional case-based method of instruction, heavily used in professional education in management, law, and medicine, typically presupposes that people can and will abstract portable schemas from individual examples. Yet, the results from Experiments $1 \mathrm{~A}$ and $1 \mathrm{~B}$ - as well as those from previous research - demonstrate that students typically show limited transfer of knowledge learned on the basis of receiving one example. Transfer is often restricted to literally similar situations - that is, situations that are similar both structurally and on the surface - rather than to the broad range of cases that embody the same principle.

The results of Experiment 2 also make it clear that comparing cases is not automatic. The noncomparison participants evidently failed to draw parallels between the cases, despite the fact that they were given only two cases, that these cases were given sequentially (and were analogous), and that they wrote out solutions for the (structurally identical) cases. Thus, even when cases follow one 
after another, there is no guarantee that people will notice their commonalities. Introducing explicit comparison across multiple cases in professional training could lead to more effective learning and transfer.

These studies broaden the range of populations and tasks with which transfer has been investigated. We found a low rate of structural transfer in negotiation (the inert knowledge phenomenon), consistent with prior studies of transfer in problem solving. Equally important, we found that these difficulties in transfer occurred for relatively expert participants (the masters of management students), who were highly motivated to understand the materials. This argues against the claim that transfer failure results from unmotivated participants working on uninteresting problems.

However, although demonstrating the generality of failure to transfer might be viewed as a pessimistic finding, there are also grounds for optimism. We found evidence that comparing cases can improve transfer, and this finding also appears to be highly general (e.g., Gick \& Holyoak, 1983; Loewenstein \& Gentner, 1997, 1999). The simple manipulation of encouraging comparison among available cases may provide an immediately beneficial practice for instructors.

Conclusions. Our results indicate that (1) comparison can be illuminating, (2) potentially useful comparisons are easy to miss, even when the cases are juxtaposed, and (3) techniques that encourage analogical encoding can lead to better learning and transfer. Three issues emerge for further research. First is the issue of long-term transfer. We are currently investigating whether the benefits of analogical encoding persist over time (Loewenstein et al., 1999). A second issue is the pedagogical question of how much training is optimal. Analogy training had similar effects in our two experiments, despite great differences in degree of training, from step-by-step guidance in the first study to a bare suggestion to compare in the second study. It would be useful to know whether such minimal methods would be effective across a wider range of learners.

A third issue is the problem of negative transfer--that is, the transfer of a principle to an inappropriate situation (see, e.g., Brown \& Campione, 1983; Chen \& Daehler, 1989; Gentner \& Toupin, 1986; Novick, 1988; Novick \& Holyoak, 1991; Ross, 1989a; Spiro, Feltovitch, Coulson, \& Anderson, 1989). In the experiments presented here, the principles learned from the examples were helpful for the problems at hand. But analogy is a two-edged sword: Any new learning powerful enough to yield correct solutions in appropriate contexts could potentially lead to incorrect solutions if misapplied. Future research should address whether the comparison technique leads to negative as well as to positive transfer.

\section{REFERENCES}

AhN, W.-K., Brewf.R, W. F., \& MoOney, R. J. (1992). Schema acquisition from a single example. Journal of Experimental Psychology: Learning, Memory, \& Cognition, 18, 39 [-412.
Bransford, J. D., Franks, J. J., Vye, N. J., \& Sherwood, R. D. (1989) New approaches to instruction: Because wisdom can't be told. In S. Vosniadou \& A. Ortony (Eds.), Similarity and analogical reasoning (pp. 470-497). New York: Cambridge University Press.

Brown, A. L., \& CAMpione, J. C. (1983). Three faces of transfer: Implications for early competence, individual differences and instruction. In M. Lamb, A. Brown, \& B. Rogoff (Eds.), Advances in developmental psychology (Vol. 3, pp. 143-192). Hillsdale, NJ: Erlbaum.

Brown, A. L., Kane, M. J., \& Echols, C. H. (1986). Young children's mental models determine analogical transfer across problems with a common goal structure. Cognitive Development, 1, 103-121.

Catrambone, R.. \& Holyoak, K. J. (1989). Overcoming contextual limitations on problem-solving transfer. Journal of Experimental Psychology: Learning, Memony, \& Cognition, 15, 1147-1156.

Chen, Z., \& DAEHLER, M. W. (1989). Positive and negative transfer in analogical problem solving by 6-year-old children. Cognitive Development, 4, 327-368.

Clement, C. A.. Mawby, R., \& Giles, D. E. (1994). The effects of manifest relational similarity on analog retrieval. Journal of Memory \& Language, 33, 396-420.

DunCKer, K. (1945). On problem-solving. Psychological Monographs, 58(5), 1-113

Falkenhainer, B., Forbus, K. D., \& Gentner, D. (1989). The structure-mapping engine: Algorithm and examples. Artificial Intelligence, 41, 1-63.

Forbus, K. D., Gentner, D., \& Law, K. (1995). MAC/FAC: A model of similarity-based retrieval. Cognitive Science, 19, 141-205.

Froman, L. A., \& Cohen, M. D. (1970). Compromise and logroll: Comparing the efficiency of two bargaining processes. Behavioral Science, 30, 180-183.

Gentner, D., Holyoak, K. J., \& Kokinov, B. N. (EDs.) (in press). The analogical mind: Perspectives from cognitive science. Cambridge, MA: MIT Press.

Gentner, D., \& Landers, R. (1985). Analogical reminding: A good match is hard to find. In Proceedings of the International Conference on Cybernetics and Society (pp. 607-613). New York: Institute of Electrical and Electronics Engineers.

Gentner, D., \& Markman. A. B. (1997). Structure-mapping in analogy and similarity. American Psychologist, 52, 45-56.

Gentner, D., Rattermann, M. J., \& Forbus, K. D. (1993). The roles of similarity in transfer: Separating retrievability and inferential soundness. Cognitive Psychology, 25, 524-575.

Gentner, D., \& Toupin, C. (1986). Systematicity and surface similarity in the development of analogy. Cognitive Science, 10, 277-300.

Gentner, D., \& WolfF, P. (1998). Metaphor and knowledge change. In E. Dietrich \& A. Markman (Eds.), Cognitive dynamics: Conceptual change in humans and machines. Cambridge, MA: MIT Press.

Gick, M. L., \& Holyoak, K. J. (1980). Analogical problem solving. Cognitive Psychology, 12, 306-355.

Gick, M. L., \& Holyoak, K. J. (1983). Schema induction and analogical transfer. Cognitive Psychology, 15, 1-38.

Hammond, K. J., Seifert, C. M., \& Gray, K. C. (1991). Functionality in analogical transfer: A hard match is good to find. Journal of the Learning Sciences, 1, I I l-152.

Holyoak, K. J., \& Кон, K. (1987). Surface and structural similarity in analogical transfer. Memory \& Cognition, 15, 332-340.

Holyoak, K. J., \& Thagard, P. R. (1995). Mental leaps: Analogy in creative thought. Cambridge, MA: MIT Press.

Keane, M. T. (1988). Analogical problem solving. New York: Ellis Horwood, Halsted Press.

Kotovsky, L., \& Gentner, D. (1996). Comparison and categorization in the development of relational similarity. Child Development, 67, 2797-2822

LASSAline, M. E., \& MURPhy, G. L. (1996). Induction and category coherence. Psychonomic Bulletin \& Review, 3, 95-99.

Lassaline, M. E., \& MurPHY, G. L. (1998). Alignment and category learning. Journal of Experimental Psychology: Learning, Memory. \& Cognition, 24, 144-160.

LAX, D. A., \& SEBENIUS, J. K. (1986). The manager as negotiator. New York: Free Press. 
LOEWENSTEIN, J., \& GENTNER, D. (1997, April). Using comparison to improve preschoolers' spatial mapping ability. Poster presented at the biennial meeting of the Society for Research in Child Development. Washington, DC.

Loewenstein, J., \& Gentner, D. (1999), Comparison and mapping in preschoolers. Manuscript submitted for publication.

Loewenstein, J., Gentner, D., \& Thompson, L. (1999). Analogical encoding and relational language in long-term transfer of negotiation strategies. Manuscript in preparation.

Markman, A. B., \& GentNer, D. (1993). Structural alignment during similarity comparisons. Cognitive Psychology, 25, 431-467.

Medin, D. L., Goldstone, R. L., \& Gentner, D. (1993). Respects for similarity. Psychological Review, 100, 254-278.

Novick, L. R. (1988). Analogical transfer, problem similarity, and expertise. Journal of Experimental Psychology: Learning. Memory, \& Cognition, 14, 510-520.

Novick, L. R., \& HolyOAK, K. J. (1991). Mathematical problem solving by analogy. Journal of Experimental Psychology: Learning, Memory \& Cognition, 17, 398-415.

Pirolli, P. L., \& ANDERson, J. R. (1985). The role of learning from examples in the acquisition of recursive programming skill. Canadian Journal of Psychology, 39, 240-272.

ReED, S. K., Dempster, A., \& EtTinger, M. (1985). Usefulness of analogous solutions for solving algebra word problems. Journal of $E x-$ perimental Psychology: Learning, Memory, \& Cognition, 11, 106-125.

REED, S. K., ERNST, G. W., \& BANERJI, R. (1974).The role of analogy in transfer between similar problem states. Cognitive Psychology, 6, 436-450.

REEVES, L. M., \& WEISBERG, R. W. (1994). The role of content and abstract information in analogical transfer. Psychological Bulletin, 115 , $381-400$.

Ross, B. H. (1984). Remindings and their effects in learning a cognitive skill. Cognitive Psychology, 16, 371-416.

Ross, B. H. (1987). This is like that: The use of earlier problems and the separation of similarity effects. Journal of Experimental Psychology: Learning, Memory, \& Cognition, 13, 629-639.

Ross, B. H. (1989a). Distinguishing types of superficial similarities: Different effects on the access and use of earlier problems. Journal of Experimental Psychology: Learning, Memory, \& Cognition, 15, 456-468.
Ross, B. H. (1989b). Remindings in learning and instruction. In S. Vosniadou \& A. Ortony (Eds.), Similarity and analogical reasoning (pp. 438-469). New York: Cambridge University Press.

Ross, B. H., \& KENNEDY, P. T. (1990). Generalizing from the use of earlier examples in problem solving. Journal of Experimental Psychology: Learning, Memory, \& Cognition, 16, 42-55.

Ross, B. H., \& KILBANE, M.C. (1997). Effects of principle explanation and superficial similarity on analogical mapping in problem solving. Journal of Experimental Psychology: Learning, Memory, \& Cognition, $23,427-440$.

Schumacher, R. M., \& Gentner, D. (1988). Transfer of training as analogical mapping. IEEE Transactions on Systems, Man, \& Cybernetics, 18, 592-600.

Simon, H. A., \& HaYes, J. R. (1976). The understanding process: Problem isomorphs. Cognitive Psychology, 8, 165-190.

Spiro, R. J., Feltovitch, P. J., Collson, R. L., \& Anderson, D. K. (1989). Multiple-analogies for complex concepts: Antidotes for analogyinduced misconception in advanced knowledge acquisition. In S. Vosniadou \& A. Ortony (Eds.), Similarity and analogical reasoning (pp. 498-531). New York: Cambridge University Press.

THOMPSON, L. (1998). The mind and heart of the negotiator. Upper Saddle River, NJ: Prentice-Hall.

Thompson, L., Gentner, D., \& Loewenstein, J. (in press). Avoiding missed opportunities in managerial life: Analogical training more powerful than case-based training. Organizational Behavior \& Human Decision Processes.

Thompson, L., \& Hrebec, D. (1996). Lose-lose agreements in interdependent decision making. Psychological Bulletin, 120, 396-409.

\section{NOTES}

1. A contingency contract is essentially a bet. In searching for a oneword label, however, we used the term safeguard with our undergraduate participants, rather than bet, after pilot studies using the term bet elicited reactions such as "I would never make a bet on a lease for my apartment." In contrast, the term safeguard did not appear to have any negative connotations for our participant population.

2. Although the difference for tradeoffs did not rise to significance, we have found significant effects in three follow-up studies. 


\section{APPENDIX A}

- The negotiation that you just saw was an example of a tradeoff.

- A tradeoff is a type of negotiation agreement in which each party gets something that they really want by giving up something that they didn't care as much about.

- An example of a tradeoff comes from a story about two sisters fighting over a single orange. Their mother intervened, and in trying to settle the matter asked each sister why she wanted the orange.
Sister l wants: Sister 2 wants:
Orange Orange

- One sister replied: "because I want the peel to make muffins."

- The other sister said: "because I want to make juice."

Sister 1 wants: $\quad$ Sister 2 wants:
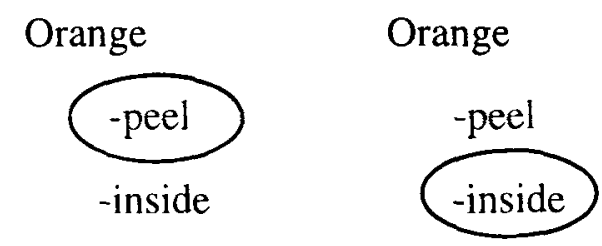

Bad Solution:

- The mother considered cutting the orange in half and giving half to each child.

- She realized, however, that this was a poor solution.

- Instead, she decided to make a tradeoff:

- She could peel the orange, give the peel to one of her children, and the inside to her other child.

- This way each child got what she really wanted by, in effect, giving up something which she did not want.
Sister 1 gets: $\quad$ Sister 2 gets:

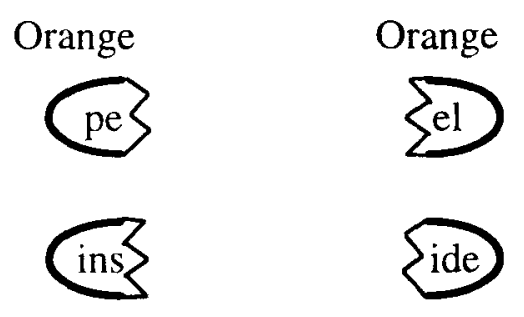

Good Solution:

Sister 1 gets: $\quad$ Sister 2 gets:

Orange Orange

-peel

-inside 
APPENDIX A (Continued)

Another example of a tradeoff is:

The Sales and Marketing divisions of a large corporation are trying to decide where to have a major conference. Sales wants to go to a lodge in the mountains. Marketing, on the other hand, wants to go a major city .

They have considered the compromise of holding two conferences, but the added cost seems prohibitive and keeping the price of the conference down is of primary importance for both Sales and Marketing.

As they discuss the issue further, it comes out that what Sales really wants is to run the conference as a retreat, which requires having a location suitable to focusing on the work at hand. Furthermore, it comes out that Marketing wants to use the conference as an opportunity to promote the company image. mountains.

The two then agree on having a well-publicized conference located in the

Below are two diagrams. The first is a diagram of the negotiation that you just read. Please fill in the corresponding boxes in the second diagram such that it describes the transcript of the negotiation that you read. After filling in the boxes, please highlight the issues which formed the tradeoff by circling the issue on which the employer received his preference, and circling the issue on which the prospective received his preference.

2.

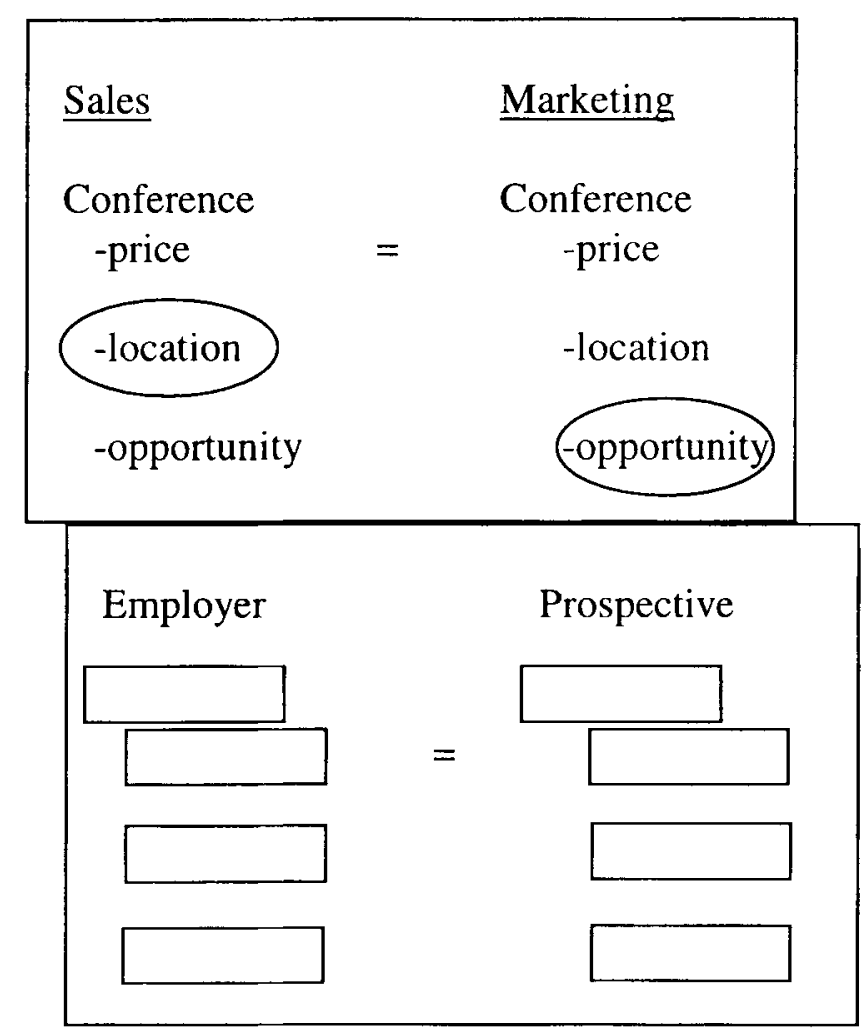


Case \#1: Syd, a recently-promoted head buyer of a major retail store, has bought some wholesale goods from an Asian merchant. All aspects of the deal have been successfully negotiated except the transfer of the goods. The merchant tells Syd that he will pay to ship the goods by boat. Syd is concerned because the US has announced that a trade embargo is likely to be placed on all goods from that country in the near future. The Asian merchant tells Syd not to worry because the boat will arrive at the US dock before the embargo occurs. Syd, however, thinks the boat will be late. Syd wants the merchant to pay to ship the goods by air freight (which is substantially more expensive). The merchant refuses because of the higher cost. They argue about when the boat will arrive.

The Asian merchant suggests that they "make a bet". The Asian merchant will ship the goods air freight but they will both watch when the boat actually docks in the US. If the boat arrives on time (as the Asian merchant believes it will), Syd will pay for all of the air freight. However, if the boat arrives late (as Syd believes it will), the Asian merchant will pay the entire air freight bill.

Case \#2: Two fairly poor brothers, Ben and Jerry, have just inherited a working farm whose main crop has a volatile price. Ben wants to sell rights to the farm's output under a long-term contract for a fixed amount rather than depend upon shares of an uncertain revenue stream. In short, Ben is risk-averse. Jerry, on the other hand is confident that the next season will be spectacular and revenues will be high. In short, Jerry is risk-seeking. The two argue for days and nights about the price of the crop for next season. Ben wants to sell now because he believes the price of the crop will fall; Jerry wants to hang onto the farm because he believes the price of the crop will increase. Jerry cannot afford to buy Ben out at this time.

Then, Jerry proposes a bet to his brother: They keep the farm for another season. If the price of the crop falls below a certain price (as Ben thinks it will), they will sell the farm and Ben will get $50 \%$ of today's value of its worth, adjusted for inflation; Jerry will get the rest. However, if the price of the crop rises (as Jerry thinks it will), Jerry will buy Ben out for $50 \%$ of today's value of the farm, adjusted for inflation, and keep all of the additional profits for himself. 